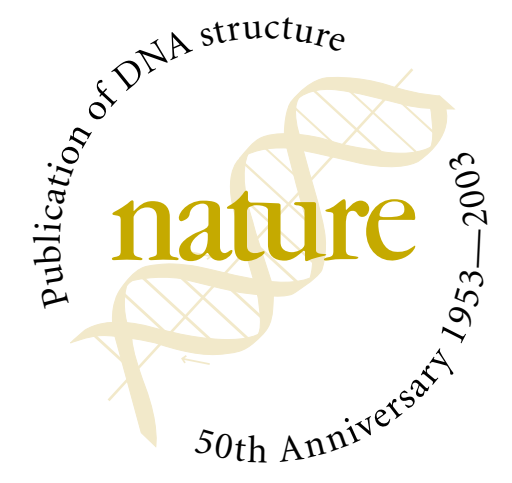

E very day, as a young postdoc, Susan Gasser gazed at a twisted wire skeleton of DNA that was collecting dust in her supervisor's office - a sculptural homage to Jim Watson and Francis Crick's epoch-making paper on the double helix ${ }^{1}$.

But Gasser now heads a molecular biology laboratory at the University of Geneva, whose members see DNA in a very different light. By shooting microscopic movies of clumped DNA in the heart of living cells, Gasser and her colleagues have shown the molecule to gyrate like a demonic dancer. For Gasser, the iconic image of DNA as a static double helix is somewhat passé: she's now fascinated with the significance of its endless acrobatics.

"The way I think about DNA is different," says Gasser, who is not alone. Watson and Crick transformed biology by revealing the three-dimensional structure of DNA - and in so doing, set the stage for a lasting obsession with its sequence of chemical letters. But 50 years on, researchers are realizing that DNA has a fascinating life in three dimensions and the fourth dimension of time - that makes it far more than a simple string of code.

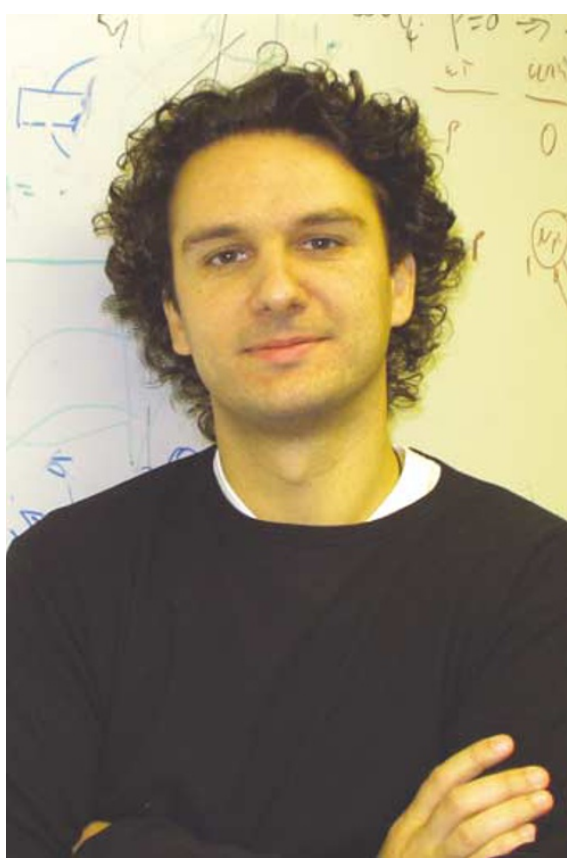
the 50th anniversary of Watson and Crick's seminal paper. But there's more to DNA than the pair's iconic structure. Helen Pearson profiles a truly dynamic molecule.

Today's studies paint a more complete picture of DNA by examining the molecule as it coils in the cell's nucleus. In this context, structural biologists now believe that DNA is frequently unfaithful to its famous structure. The double helix, it has emerged, regularly morphs into alternative shapes and weaves itself into knots.

Cell biologists, meanwhile, are exposing the surprisingly dynamic life of the molecule after it crumples up into chromosomes. Thelatter form fleeting liaisons with pro-

teins, jiggle around impatiently and shoot out exploratory arms. The nucleus, like DNA, was once thought to be fairly static, recalls structural biologist Alexander Rich of the Massachusetts Institute of Technology in Cambridge. "Now we know it to be a very lively place," he says.

Some researchers believe that these mysterious movements may be just as important as the genetic sequence itself in deciding which genes are switched on and off. They even have tantalizing evidence that a failure to coordinate this subcellular waltz could underlie some human diseases. Half a century may have passed since the double helix made its debut, but in some ways, scientists have only just begun to understand this miraculous molecule as it twirls in time and space.

The realization that the double helix isn't the be-all and end-all of genetics stems partly from the discovery by structural biologists of DNA posed in other weird and wonderful shapes. More than two decades ago, Rich first determined the structure of one such variant, called Z-DNA (ref. 2). Although still a double

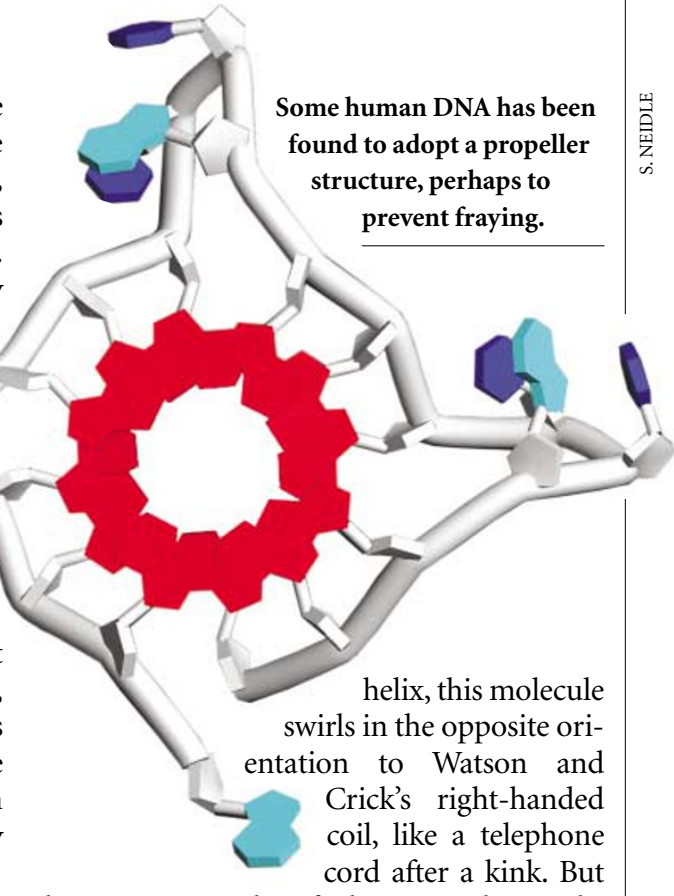

because it was identified in test-tube conditions, the left-handed Z-DNA wasn't considered a significant player in cellular life.

Only recently have researchers found evidence that Z-DNA might be vital in controlling gene activity. In 2001, a team led by Keji Zhao of the National Heart, Lung, and Blood Institute in Bethesda, Maryland, showed that part of the regulatory sequence of an immune-system gene must flip into Z-DNA before the gene can be activated ${ }^{3}$.

Zhao and other biologists now believe that similar stretches of transiently existing ZDNA, of which there are perhaps 100,000 in the human genome, may help to switch on genes by making them more accessible to proteins, such as transcription factors, that stimulate gene activity. Building on this idea, Rich

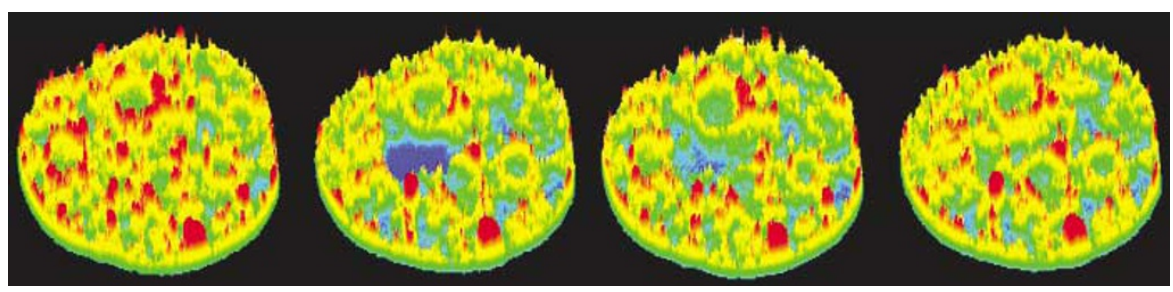

Light show: Tom Misteli (left) has shown the hustle and bustle of proteins in the cell's nucleus. In this time-lapse sequence, a spot (blue) is bleached using a laser, but fluorescent proteins soon diffuse into it. 


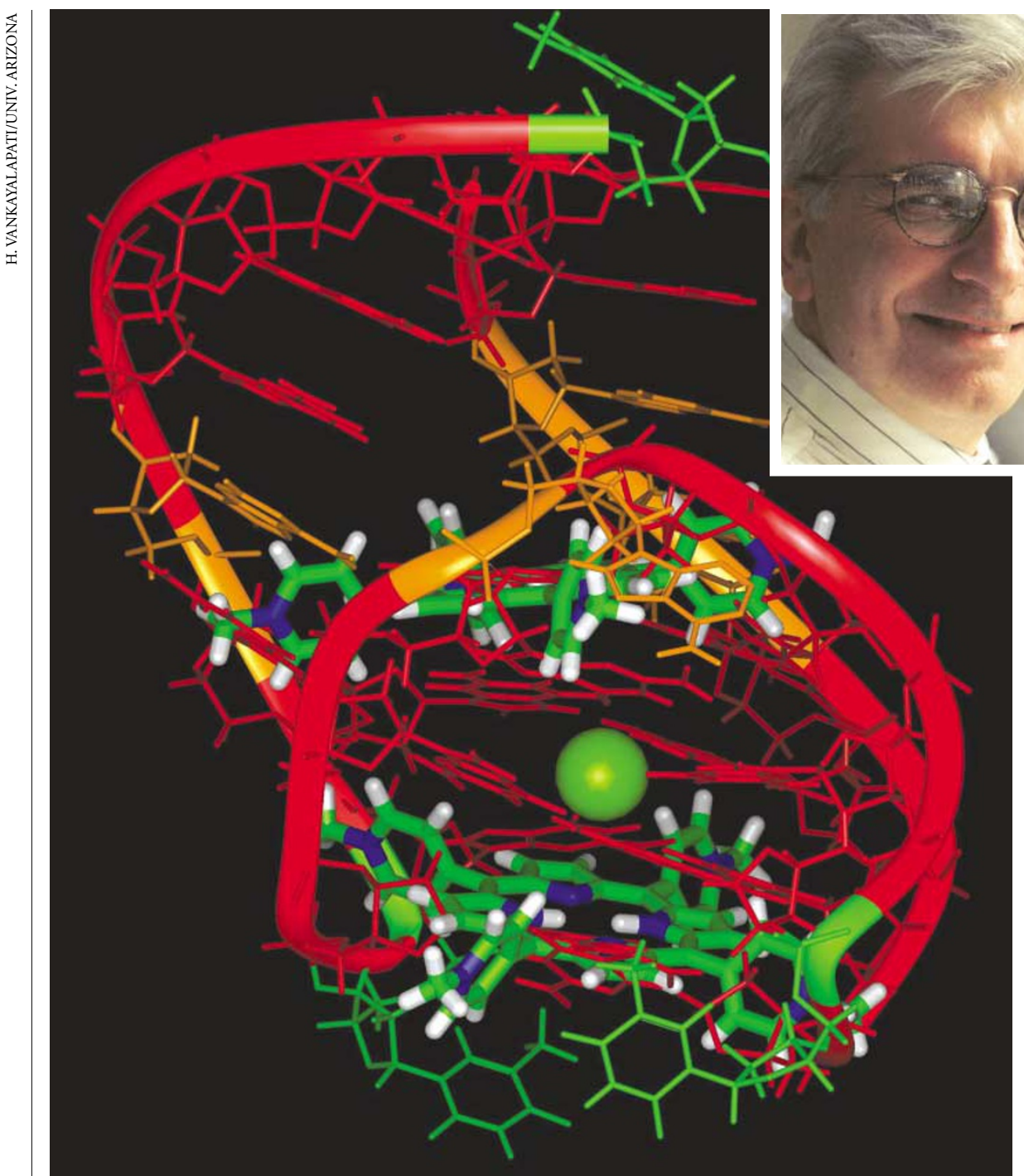

Laurence Hurley (inset) thinks this G-quadruplex structure (red) prevents activation of a cancer gene.

already has evidence that the vaccinia virus, which is related to smallpox, may specifically hijack vulnerable Z-DNA, thereby crippling human cells. In unpublished work on mice, he has found that preventing a viral protein from binding to Z-DNA weakens an infection.

Besides the helix's jumps and twists, DNA may also morph into shapes that are a world away from the familiar spiral. Last year, Stephen Neidle of the Institute of Cancer Research in London unveiled one such form that is adopted at the ragged ends of chromosomes, known as telomeres, where the two sister strands give way to a lone string. Using $\mathrm{X}$-ray crystallography, he showed that this single strand can weave itself into a tidy propeller-like loop, which may help to prevent the molecule from fraying away ${ }^{4}$. "It goes well beyond the linear double helix," says Neidle, who is now at the University of London School of Pharmacy.

Neidle's propeller-like structure belongs to a class of departures from helical forms of DNA known as 'G-quadruplexes', which occur in sequences that are rich in guanine, one of the four letters of the genetic code.
Another member of the class may prevent genes from being switched on. Last summer, Laurence Hurley of the University of Arizona in Tucson showed that one type of Gquadruplex forms next to the potent cancercausing gene $c-M Y C$. Negating this structure by mutating its genetic sequence boosted the gene's activity. Hurley suspects that the shape wards off gene-activating proteins, and he is now searching for drugs that could help to stabilize G-quadruplexes and thus serve as anti-cancer agents.

Even in its standard, helical form, DNA is throwing up surprises. The molecule has long been known to form intimate relationships with proteins that help it to fold, and trigger or subdue gene activity. Until recently, these liaisons were thought mostly to be fixed, or to change only slowly with time. But imaging technology has allowed biologists to watch living cells in real time.

The resulting videos exposed an unexpected hubbub in the activity of proteins buzzing around DNA. "It changed the way we thought about the nucleus," says Tom this idea has collapsed, as improved cellular
Misteli of the National Cancer Institute in Bethesda. "The word 'static' is disappearing from our vocabulary."

Misteli's is one of several groups that took the lid off this nuclear ants' nest, using a technique called fluorescence recovery after photobleaching (FRAP). The researchers blasted lasers at live cells containing fluorescent proteins, bleaching out the fluorescence in a small spot of the nucleus. To Misteli's surprise, glowing proteins from elsewhere in the nucleus rushed in to fill the void ${ }^{6}$.

Many researchers now believe that almost all nuclear proteins are scuttling constantly back and forth, moving at speeds that would allow them to traverse the nucleus in as little as five seconds. Even histone $\mathrm{H} 1$, a protein that was thought to sit cuddled in the arms of DNA, now appears to attach and detach itself every minute or $\mathrm{so}^{7,8}$. Although one might think that such turmoil would detract from the orderly functioning of DNA, Misteli speculates that this swirl of proteins helps cells to regulate gene activity. It may allow genes to sample constantly from the soup of transcription factors and other regulatory proteins that are milling around the nucleus.

\section{Food for thought}

This conjures up a picture of DNA as a tangle of noodles swilling lazily around in a nourishing molecular soup. But in fact, stuffing some two metres of DNA into a nucleus one-millionth of this width requires some exquisitely careful packing. DNA wraps itself around histone proteins to form a nodular structure called chromatin, which in turn coils up like an overtwisted string into globular chromosomes.

Over the past few years, researchers have come to realize that chromosomes, which seem to be carefully arranged in the nucleus, may be positioned so that those that are most important to the cell gain preferential spots. Wendy Bickmore and her colleagues at the UK Medical Research Council's Human Genetics Unit in Edinburgh have shown that human chromosome 18 , which carries only a handful of active genes, is relegated to the edge of the nucleus, whereas the genepacked chromosome 19 sits near the middle 9 . Other researchers have revealed that this organization is preserved in the cells of primates from humans to monkeys ${ }^{10}$.

The fact that this chromosomal positioning has been maintained over some 30 million years of divergent primate evolution suggests that the order in which chromosomes are packed in the nucleus is functionally important - but exactly what purpose this packing serves remains unclear. Some scientists suggest that pushing a chromosome to the edge of the nucleus may help to 

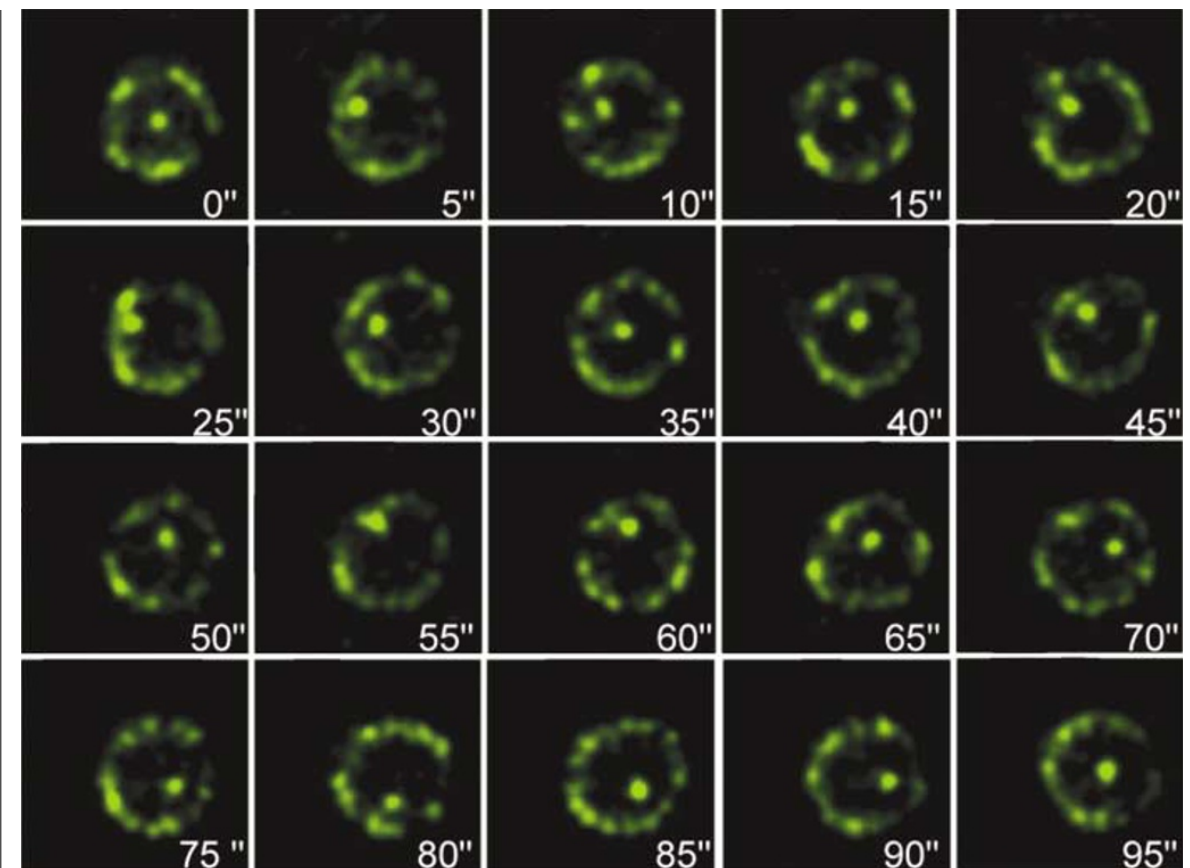

Room to manoeuvre: these time-lapse images show how a yeast chromosome roams around the nucleus.

hive it off from gene-activating machinery and keep unwanted genes gagged. But Bickmore suspects that peripheral chromosomes may act as defensive 'padding' for the nucleus' valuable genetic cargo, shielding DNA from mutagenic chemicals. "It might be to protect the most important part of the genome from damage," she speculates.

Studies of chromosomal positions used to involve dead cells fixed on microscope slides. But over the past few years, it has also become possible to watch chromosomes in action, thanks largely to a technique for filming a gene's location in living cells that was developed by Andrew Belmont's team at the University of Illinois at Urbana-Champaign. Belmont engineered mammalian cells to carry multiple copies of a bacterial DNA sequence, which can be tagged by a fluorescent bacterial protein ${ }^{11}$.

Using Belmont's system, researchers have shown chromosomes to be constantly in motion. Chromosomes in cells from yeast to mammals all appear to shimmy around by diffusion within their confined territories, wiggling frantically from second to second ${ }^{12}$. Gasser is one of the biologists who has watched these antics, and believes that the shuddering motion helps Misteli's scudding proteins to find their targets in the vast genome. "Before, it was almost inconceivable how a protein would find its binding site," she says.

Chromatin also pulls off some more impressive stunts. Belmont, for example, has engineered mammalian cells to carry a large array of bacterial genes that can be switched on, and tagged, by a fluorescent activating protein. Within several hours of being turned on, the genes unfurl from dense spots of chromatin into diffuse fibres ${ }^{13}$. Applying the same trick to a smaller cluster of bacterial genes caused its chromatin to move a good distance from the edge of the nucleus towards its interior ${ }^{14}$.

Meanwhile, Amanda Fisher and her colleagues at Imperial College, London, have shown that chromatin's wanderings may help to lock unwanted genes in an 'off' configuration. In developing immune cells, Fisher demonstrated that chromatin carrying genes that are no longer needed moved close to regions of inactive DNA called heterochromatin, which is thought to suppress neighbouring genes. If this relocation did not occur, the genes reactivated ${ }^{15}$.

\section{Cause and effect?}

But Fisher is the first to point out the problem with such observations: they may link DNA movement to changes in gene activity, but they do not prove that one causes another. Some scientists maintain that a wandering genome might simply be a passive consequence of the hustle of proteins around it. But researchers led by John Sedat of the University of California, San Francisco, have provided evidence to the contrary. They studied a mutant version of an eyecolour gene in the fruitfly Drosophila, which tends to manoeuvre itself next to genetically mute heterochromatin on the outskirts of the nucleus. The researchers found that, unusually, the dysfunctional gene drags with

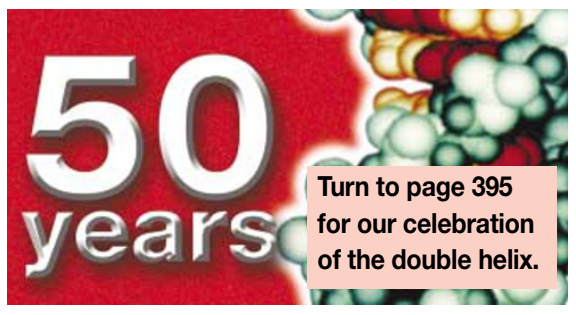

it a normal copy of the gene on its partner chromosome - and that, when this happens, the normal copy is also switched off ${ }^{16}$.

With such tantalizing signs that chromosomal and chromatin movements may spark or silence gene activity, some scientists are asking whether disruptions in location could trigger disease. Misteli, for example, has gathered evidence that in mouse lymphoma cells, chromosomes 12, 14 and 15 huddle closer together than normal ${ }^{17}$. He suspects that their proximity might be what predisposes the cells to become cancerous, by facilitating the abnormal exchange of chromosome regions that can trigger uncontrolled cell division.

Such work implies that patients with a susceptibility to cancer might be diagnosed on the basis of the positions of their chromosomes within the nucleus. With this in mind, Robert Singer of the Albert Einstein College of Medicine in New York has developed a technique that takes a snapshot of the positions of active genes in a single cell. This could be used, for example, to help pathologists to examine a breast biopsy or a suspect skin mole.

The team created 11 fluorescent tags of different colours, and washed them over human cells. Each sticks to the molecules produced by one specific gene, revealing how active it is and its location in the nucleus ${ }^{18}$. Looking ahead, others are honing this technique in order to watch human genes in action. They hope to combine multi-coloured tags that will flag not just DNA, but also the messenger RNA molecules churned out by active genes, and the proteins that they encode.

Such developments promise to bring further insights into DNA's enigmatic life in space and time - marking a new chapter in the molecule's history. "Watson and Crick must have thought that sequence was everything," reflects Peter Cook, who studies the structure and function of the cell nucleus at the University of Oxford, UK. "But life is much more complicated than that."

Helen Pearson works in Nature's news syndication team.

1. Watson, J. D. \& Crick, F. H. C. Nature 171, 737-738 (1953).

2. Wang, A. H.-J. et al. Nature 282, 680-686 (1979).

3. Liu, R. et al. Cell 106, 309-318 (2001).

4. Parkinson, G. N., Lee, M. P. H. \& Neidle, S. Nature 417, 876-880 (2002)

5. Siddiqui-Jain, A., Grand, C. L., Bearss, D. J. \& Hurley, L. H. Proc. Natl Acad. Sci. USA 99, 11593-11598 (2002).

6. Phair, R. D. \& Misteli, T. Nature 404, 604-609 (2000).

7. Lever, M. A., Th’ng, J. P. H., Sun, X. \& Hendzel, M. J. Nature 408, 873-876 (2000).

8. Misteli, T., Gunjan, A., Hock, R., Bustin, M. \& Brown, D. T. Nature 408, 877-881 (2000).

9. Croft, J. A. et al. J. Cell Biol. 145, 1119-1131 (1999).

10. Tanabe, H. et al. Proc. Natl Acad. Sci. USA 99, 4424-4429 (2002). 11. Robinett, C. C. et al. J. Cell Biol. 135, 1685-1700 (1996).

12. Marshall, W. F. Curr. Biol. 12, R185-R192 (2002).

13. Tumbar, T., Sudlow, G. \& Belmont, A. S. J. Cell Biol. 145, 1341-1354 (1999).

14. Tumbar, T. \& Belmont, A. S. Nature Cell Biol. 3, 134-139 (2001). 15. Brown, K. E., Baxter, J., Graf, D., Merkenschlager, M. \& Fisher, A. G. Mol. Cell 3, 207-217 (1999).

16. Dernburg, A. F. et al. Cell 85, 745-759 (1996).

17. Parada, L. A., McQueen, P. G., Munson, P. J. \& Misteli, T. Curr. Biol. 12, 1692-1697 (2002).

18. Levsky, J. M., Shenoy, S. M., Pezo, R. C. \& Singer, R. H. Science 297, 836-840 (2002) 